\title{
Staphylococcus aureus as an infectious agent: overview of biochemistry and molecular genetics of its pathogenicity
}

\author{
Konrad Plata ${ }^{1,2}$, Adriana E. Rosato ${ }^{2}$ and Grzegorz Węgrzyn ${ }^{1 凶}$ \\ ${ }^{1}$ Department of Molecular Biology, University of Gdańsk, Gdańsk, Poland; ${ }^{2}$ Division of Infectious Diseases, De- \\ partment of Internal Medicine, Virginia Commonwealth University, Richmond, USA
}

Received: 22 November, 2009; revised: 07 December, 2009; accepted: 10 Decemebr, 2009

available on-line: 11 December, 2009

\begin{abstract}
Although it is estimated that $20-30 \%$ of the general human population are carriers of Staphylococcus aureus, this bacterium is one of the most important etiological agents responsible for healthcare-associated infections. The appearance of methicillin resistant S. aureus (MRSA) strains has created serious therapeutical problems. Detailed understanding of the mechanisms of $S$. $a u-$ reus infections seems necessary to develop new effective therapies against this pathogen. In this article, we present an overview of the biochemical and genetic mechanisms of pathogenicity of $S$. aureus strains. Virulence factors, organization of the genome and regulation of expression of genes involved in virulence, and mechanisms leading to methicilin resistance are presented and briefly discussed.
\end{abstract}

Keywords: Staphylococcus aureus, virulence, pathogenicity genes, toxins, methicillin resistance

\section{BIOCHEMISTRY AND MOLECULAR GENETICS OF STAPHYLOCOCCUS AUREUS}

Staphylococcus aureus is a Gram-positive spherical bacterium approximately $1 \mu \mathrm{m}$ in diameter. Its cells form grape-like clusters, since cell division takes place in more than one plane. It is often found as a commensal associated with skin, skin glands, and mucous membranes, particularly in the nose of healthy individuals (Crossley \& Archer, 1997). It has been estimated that approx. $20-30 \%$ of the general population are S. aureus carriers (Heyman, 2004). On a rich medium, $S$. aureus forms medium size "golden" colonies. On sheep blood agar plates, colonies of $S$. aureus often cause $\beta$-hemolysis (Ryan \& Ray, 2004). The golden pigmentation of $S$. aureus colonies is caused by the presence of carotenoids and has been reported to be a virulence factor protecting the pathogen against oxidants produced by the immune system (Liu et al., 2005).

Staphyloccoci are facultative anaerobes capable of generating energy by aerobic respiration, and by fermentation which yields mainly lactic acid. Staphylococcus sp. is catalase-positive, a feature differentiating them from Streptococcus sp., and they are oxidase-negative and require complex nutrients, e.g., many amino acids and vitamins B, for growth. $S$. aureus is very tolerant of high concentrations of sodium chloride, up to 1.7 molar.

Another feature of the Staphylococcus genus is the cell wall peptidoglycan structure that contains multiple glycine residues in the crossbridge, which causes susceptibility to lysostaphin (Crossley \& Archer, 1997). S. aureus produces coagulase which interacts with prothrombin in the blood causing plasma to coagulate by converting fibrinogen into fibrin.

${ }^{\square}$ Corresponding author: Grzegorz Węgrzyn, Department of Molecular Biology, University of Gdańsk, Kładki 24, 80-822 Gdańsk, Poland; tel.: (48) 58523 6308; fax: (48) 58523 5501; e-mail: wegrzyn@biotech.univ.gda.pl

Abbreviations: AIP, auto-inducing peptide; IS, Insertion sequences; MRSA, methicillin resistant Staphylococcus ureus; MSSA, methicillin sensitive S. aureus; MSCRAMMs, microbial surface components recognizing adhesive matrix molecules; PBPs, penicillin-binding proteins; PNAG, poly- $N$-acetylglucosamine; PVL, Panton-Valentine leukocidin; SCVs, small-colony variants; SaPIs, superantigen toxins; SCCmec, staphylococcal cassette chromosome mec; TSST, toxic shock syndrome toxin. 
Blood coagulation is used to distinguish S. aureus from others members of the genus, which are collectively designated as coagulase-negative staphylococci (Ryan \& Ray, 2004). Since it is a frequent ethological agent of human diseases and exhibits resistance to a growing number of therapeutic agents, $S$. aureus is also one of the most intensively studied bacterial species.

\section{S. AUREUS INFECTIONS}

S. aureus is a commensal and a pathogen. The anterior nares are the major site of colonization in humans. About $20-30 \%$ of individuals are persistent carriers of S. aureus, which means they are always colonized by this bacterium, and $30 \%$ are intermittent carriers (colonized transiently) (Wertheim et al., 2005). Colonization significantly increases the risk of infections since it provides a reservoir of the pathogen from which bacteria are introduced when host defense is compromised (Kluytmans et al., 1997). Patients with $S$. aureus infections are usually infected with the same strain that they carry as a commensal (Williams et al., 1959).

S. aureus is one of the main causes of hospital- and community-acquired infections which can result in serious consequences (Diekema et al., 2001). Nosocomial S. aureus infections affect the bloodstream, skin, soft tissues and lower respiratory tracts. S. aureus can be a cause of central venous catheter-associated bacteremia and ventilator-assisted pneumonia. It also causes serious deep-seated infections, such as endocarditis and osteomyelitis (Schito, 2006). In addition to the infections listed above, $S$. aureus is often responsible for toxin-mediated diseases, such as toxic shock syndrome, scalded skin syndrome and staphylococcal foodborne diseases (SFD). Hospitalized patients are particularly exposed to $S$. aureus infections due to their compromised immune system and frequent catheter insertions and injections (Lindsay \& Holden, 2004). The SENTRY Surveillance Program investigating worldwide $S$. aureus infections during a two-year period has revealed that this pathogen is the leading cause of bloodstream, lower respiratory tract and skin/soft tissues infections in all regions surveyed (Diekema et al., 2001). The importance of this human pathogen, apart from its ability to cause life-threatening infections, is its remarkable potential to develop antimicrobial resistance.

\section{VIRULENCE FACTORS}

S. aureus is equipped with a great variety of virulence factors, which include both structural and secreted products participating in pathogenesis of infection.

\section{Attachment-improving agents}

S. aureus carries numerous surface proteins named "microbial surface components recognizing adhesive matrix molecules" (MSCRAMMs) that mediate attachment to host tissues and initiate colonization leading to an infection (Gordon \& Lowy, 2008). Fibronectin binding proteins A and B (Fnb$\mathrm{pA}$ and $\mathrm{FnbpB}$ ) participate in attachment of bacterial cells to an extra-cellular matrix component, fibronectin, and to plasma clot. Collagen binding protein, Cna, is necessary for adherence of $S$. aureus to collagenous tissues and cartilage (Switalski et al., 1993) and it has been shown that antibodies against Cna block the bacteria attachment to those tissues (Patti et al., 1994). Clumping factor A and B (ClfA and $(\mathrm{ClB})$ mediate clumping and adherence of bacterial cells to fibrinogen in the presence of fibronectin. Clumping factors are thought to play a significant role in wound and foreign body infections and it has been shown that $c l f A$ mutant is less virulent than the wild type isogenic strain (Foster \& Hook, 1998). Plasma-sensitive surface protein (Pls), once processed by plasmin, participates in binding to both fibrinogen and fibronectin (Hauck \& Ohlsen, 2006). Protein A is a hallmark of S. aureus which is encoded by the spa gene and is a cell wall-associated protein that binds to the Fc domain of immunoglobin G (IgG). Protein A binds IgG in "wrong orientation" on the surface of $S$. aureus cells which is thought to disrupt opsonization and phagocytosis (Switalski et al., 1993). Protein A also exhibits an ability to bind to von Willebrand factor, a protein present at sites of damage of endothelium, and as a result, it can play a role in adherence and induction of endovascular diseases by S. aureus (Hartleib et al., 2000).

Implanted biomedical device-related S. aureus infections depend on the pathogen's ability to attach to the surface of the biomaterial and consequently to form a mucoid biofilm. Biofilms are complex bacterial populations which are surface-attached and enclosed in a polysaccharide matrix, composed of poly- $N$-acetylglucosamine (PNAG). PNAG production depends on proteins encoded by the ica (intracellular adhesion) operon (Fitzpatrick et al., 2005). Biofilm-associated bacteria, unlike their planktonic counterparts, are resistant to the host immune responses and to antimicrobials, which often complicates treatment. It was reported that $60 \%$ of $S$. aureus strains were able to produce biofilm (Arciola et al., 2001a; 2001b). However, contradictory results obtained by other investigators suggested that all S. aureus strains possess the icaADBC genes (Rohde 
et al., 2001). In addition, there is a regulatory gene called icaR that, together with the icaA promoter, is subject to a multitude of regulatory effects linking ica gene expression to virulence regulators.

Recent studies indicated that among clinical isolates of S. aureus, only between $45 \%$ and $70 \%$ (depending on the type of infection) strains were able to form biofilm (Grinholc et al., 2007). Those studies also suggested that no correlation exists between biofilm production and the type of staphylococcal infection.

\section{Exotoxins}

One of the important characteristics of $S$. aureus is its capability to secrete toxins that disrupt membranes of host cells. Cytolytic toxins form $\beta$-barrel pores in the cytoplasmic membranes and cause leakage of the cell's content and lysis (Foster, 2005). S. aureus secrets several cytolytic toxins, among them alpha-hemolysin, beta-hemolysin, gamma-hemolysin, leukocidin, and Panton-Valentine leukocidin (PVL) (Kaneko \& Kamio, 2004). Alpha-hemolysin, encoded by the hla gene, inserts into eukaryotic membranes and oligomerizes into a $\beta$-barrel that forms a pore which causes osmotic cytolysis. Alpha-hemolysin is particularly cytolytic toward human platelets and monocytes (Menestrina et al., 2001).

PVL is classified as a bicomponent cytolysin because it is dependent on two secreted proteins (LukF-PV and LukS-PV) that insert into the host's cytoplasmic membrane and hetero-oligomerize to form a pore (Kaneko \& Kamio, 2004). PVL exhibits a high affinity toward leukocytes and is mostly associated with community-acquired methicillin resistant $S$. aureus (CA-MRSA) which causes severe necrotizing pneumonia and contagious skin infections (Foster, 2005). Other bicomponent toxins, gammahemolysin (Hlg) and leukocidin (Luk), are cytotoxic toward erythrocytes and leukocytes, respectively (Kaneko \& Kamio, 2004).

\section{Superantigen toxin}

S. aureus generates a group of powerful immuno-stimulatory proteins implicated in gastroenteritis and toxic shock syndrome. They are resistant to heat denaturation and proteases. These toxins have the ability to cross-link MHC class II molecules located on antigen-presenting cells with T-cell receptors, forming a trimolecular complex. Formation of the complex induces intense T-cell proliferation in an antigen-independent manner resulting in massive cytokine production and release which causes capillary leak, epithelial damage and hypotension (Baker \& Acharya, 2004). The primary function of superantigens is thought to weaken the host's immune sys- tem sufficiently to allow the pathogen to propagate and the disease to progress (Kotzin et al., 1993). The staphylococcal enterotoxins A, B, C, D, E, G, Q are responsible for staphylococcal foodborne diseases and toxic shock syndrome, while TSST- 1 is the cause of toxic shock syndrome (Baker \& Acharya, 2004). The superantigen toxins are typically encoded by mobile genetic elements (Novick, 2003b) which will be described in later sections.

\section{SMALL-COLONY VARIANTS}

Small-colony variants (SCVs) represent a subpopulation of naturally occurring, slowly growing $S$. aureus with distinct phenotype and pathogenetic features. SCVs have been reported to cause recurrent, persistent infections many years after the initial infection had been cured (Proctor et al., 1995). Very often they reside inside human cells avoiding host defenses and antimicrobial chemotherapeutics. SCVs are defective in their electron transport pathways and usually form non-pigmented, non-hemolytic tiny colonies on agar (Kaneko \& Kamio, 2004). The small-colony variants display marked auxotrophisms for thymidine, menadione and/or hemin (Clements et al., 1999; Bates et al., 2003; Lannergard et al., 2008; von Eiff, 2008). They exhibit reduced rate of metabolism and are less virulent, but due to their slow growth and reduced cell wall synthesis, they are more tolerant of $\beta$-lactam antibiotics than their wild-type parents. Their low membrane potential makes them also resistant to aminoglycoside antibiotics (Proctor et al., 2006).

\section{REGULATION OF GENES INVOLVED IN VIRULENCE}

The genes coding for virulence factors are regulated in a tightly coordinated manner that is synchronized with the biological cycle of $S$. aureus. The production of factors involved in virulence is controlled by quorum sensing mechanism. In $S$. aureus, genes coding for surface proteins are down regulated during early stages of the growth whereas genes that encode secreted proteins are up regulated in late exponential phase. This pattern of gene expression in which surface proteins involved in adhesion and defense against host's immune system (protein A, coagulase, fibronectin binding proteins, among many others) are synthesized before production of secreted hemolysins, cytotoxins, proteases and other degradative enzymes seems to reflect a strategy of $S$. aureus in which the pathogen first establishes itself in the host and only then attacks it. This regulation is, in large part, due to the accessory gene regulator 
(agr) two component system (Novick \& Geisinger, 2008).

The agr locus consists of two divergent transcription units RNAII and RNAIII driven by two promoters, P2 and P3, respectively (Janzon \& Arvidson, 1990). The P2 transcript, RNAII, contains four cistrons: $\operatorname{agr} A, \operatorname{agr} B, \operatorname{agr} C$ and $\operatorname{agr} D$. The sensor, AgrC, and the response regulator, AgrA, comprise the two component system that responds to auto-inducing peptide (AIP). This peptide is present in the extracellular environment and drives transcription from both $\mathrm{P} 2$ and $\mathrm{P} 3$ promoters. agrD encodes the auto-inducing peptide, which is posttranslationally modified and secreted by AgrB (Novick, 2003a). The effector molecule of the agr system is a 514-nt transcript, derived from the P3 promoter, called RNAIII, which also carries the hld cistron that codes for delta-hemolysin. RNAIII stimulates the expression of post-exponentially synthesized extracellular toxins and enzymes and represses synthesis of exponentialphase surface proteins (Janzon \& Arvidson, 1990). RNAIII acts primarily as an antisense RNA for translational activation of certain mRNAs or binds to the ribosome binding site in the case of repressed mRNAs, preventing ribosome binding and inducing fast mRNA degradation by endoribonuclease III (Morfeldt et al., 1995; Boisset et al., 2007).

\section{ORGANIZATION OF THE S. AUREUS GENOME}

The first genome sequences of $S$. aureus strains Mu50 and N315 were published in 2001 (Kuroda et al., 2001). At present, complete genomic sequences of ten $S$. aureus strains are available, and the genomes of several others have been partially determined (Kuroda et al., 2001; Baba et al., 2002; Gill et al., 2005; Diep et al., 2006). The genome of $S$. aureus is a circular chromosome that is $2.8-2.9 \mathrm{Mbp}$ in size, with a $\mathrm{G}+\mathrm{C}$ content of about 33\% (Crossley \& Archer, 1997). The chromosome encodes approximately 2700 CDSs (protein coding sequences) as well as structural and regulatory RNAs. It has been proposed that the $S$. aureus genome is composed of the core genome, accessory component and foreign genes.

The core genes are present in more than $95 \%$ of isolates, represent $75 \%$ of any S. aureus genome and determine the backbone of the genome. The organization of the core component is highly conserved and the identity of individual genes between isolates is $98-100 \%$. The majority of core genes are associated with fundamental functional categories of housekeeping functions and central metabolism.

The accessory component includes genetic regions present in 1-95\% of isolates and accounts for about $25 \%$ of any S. aureus genome. It typically consists of mobile genetic elements that have or previ- ously had the ability of horizontal transfer between strains. These genetic elements include pathogenicity islands, genomic islands, prophages, chromosomal cassettes and transposons (Lindsay \& Holden, 2004).

\section{Pathogenicity islands}

The family of staphylococcal pathogenicity islands that carry genes for superantigen toxins (SaPIs) are $15-20 \mathrm{~kb}$ elements located at constant positions in the chromosome. SaPIs possess certain bacteriophage-related attributes: genes coding for integrases, helicases and terminases, and flanking direct repeats (Novick, 2003b). The archetype of this family, SaPI1, codes for toxic shock syndrome toxin TSST (tst) and is excised and induced to replicate as well as transduced at high frequency by phage $80 \alpha$. DNA of SaPI1 is encapsulated into $80 \alpha$ phage-like particles for transfer (Lindsay et al., 1998; Ruzin et al., 2001). Another member of SapI family, SapI3, encodes enterotoxin B and is thought to be mobilized and encapsulated by phage 29 (Novick, 2003b). Certain bovine isolates of S. aureus carry SaPlbov1 which encodes toxin shock syndrome toxin $(t s t)$ and can be induced by three phages: 80 $\alpha, \phi 11$ and $\phi 147$ (Ubeda et al., 2005). Members of the SaPI family have been found in almost all strains of $S$. aureus sequenced so far (Kuroda et al., 2001; Baba et al., 2002; Diep et al., 2006).

In addition to SaPIs, $S$. aureus strains contain genomic islands from the $v \mathrm{Sa}$ family. These islands carry genes coding for about half of the $S$. aureus toxins and virulence factors, and greatly contribute to the pathogenicity of this species (Gill et al., 2005). They are found in all sequenced strains in the same locations and some of the genes carried by them are highly conserved (Lindsay \& Holden, 2004). They encode their own integrase and usually are spontaneously excised from the host chromosome (Baba et al., 2002). Members of this family of genomic islands include, but are not limited to, vSa1 (carrying enterotoxin genes seb, tsst, ear), vSa2 (containing genes encoding enterotoxine (sec) and toxic shock syndrome toxine - (tsst)) (Gill et al., 2005). Other examples include $v \mathrm{Sa} \alpha$ and $v \mathrm{Sa} \beta$, which are found in all sequenced isolates and have a defective transposase gene, and therefore are not excised from the chromosome. Additionally they carry a cassette encoding a restriction-modification system and genes encoding leukocidin (lukDE) (Baba et al., 2002).

\section{Prophages}

Prophages of S. aureus can be classified into three groups based on the size of their genome. Class I includes phages with genomes of less than $20 \mathrm{~kb}$, class II has a genetic material of approximately $40 \mathrm{~kb}$ and class III of more than $125 \mathrm{~kb}$ (Kwan 
et al., 2005). Prophages are thought to play an important role in evolution and pathogenicity of $S$. aureus and very often offer means for the horizontal transfer of genetic information. Each of the S. aureus strains sequenced so far contains between one and three prophages, most of them carry virulence determinants exemplified by enterotoxins A, G, K, exfoliative toxin, staphylokinase and Panton-Valentine Leukocidin (Kuroda et al., 2001; Lindsay \& Holden, 2004; Diep et al., 2006).

\section{Insertion sequences and transposons}

Insertion sequences (IS) carry at least one gene coding for a transposase which participates in the recombination required for transposition. Most IS elements also contain short inverted terminal repeats acting as transposase binding sites (Baba et al., 2004). Insertion elements are randomly scattered throughout the genome of $S$. aureus, both in coding and non-coding regions. In MRSA, S. aureus N315 and Mu50 strains, eight copies of IS1181 have been found (Kuroda et al., 2001; Gill et al., 2005).

Transposons are larger transposable genetic elements that, in addition to a transposase gene, carry other genes which very often are antibiotic resistance determinants. S. aureus is the host to more than ten transposons, the majority of which carry antibiotic resistance genes (Baba et al., 2004).

\section{Plasmids}

Plasmids, defined as extrachromosomal genetic elements bearing only non-essential genes which, however, may provide a benefit to the host under special environmental conditions, often encode factors determining resistance to antibiotics or heavy metals, virulence factors and proteins facilitating survival in the presence of unusual nutrients (Wegrzyn, 2005). Plasmids of S. aureus have been categorized into three classes. Class I plasmids are of the size of $1-5 \mathrm{~kb}$ and occur in high copy number (15-50 per cell). They usually carry a single antibiotic resistance determinant. The class II plasmids are of intermediate size and occur in intermediate copy number, and they usually code for $\beta$-lactamase and confer resistance to inorganic ions. The last group of staphylococcal plasmids, class III, consists of large conjugative plasmids $(40-60 \mathrm{~kb})$. Class III plasmids carry multiple resistance determinants, exemplified by resistance to trimethoprim, gentamycin and ethidium bromide (Novick, 1989). The plasmids often can serve as means by which antibiotics resistance is transmitted. Moreover, the conjugative plasmids encode their own conjugative horizontal transfer mechanism by tra genes that offer an advantage by which transfer of extrachromosal genetic information to other bacteria occurs (Hartleib et al., 2000; Kuroda et al., 2001; Holden et al., 2004 ; Gill et al., 2005; Diep et al., 2006).

\section{METHICILLIN RESISTANT S. AUREUS (MRSA)}

Methicillin resistant Staphylococcus aureus (MRSA) is defined by the presence of a large mobile genetic element called staphylococcal cassette chromosome, mec (SCCmec). It carries the mecA gene that codes for an alternative penicillin binding protein, PBP2a, with low binding affinity to all $\beta$-lactams (described in next sections) (Ito et al., 1999). MRSA strains were first described in hospital settings, after the introduction of $\beta$-lactamase-insensitive penicillins into medical practice, and they continue to be a serious problem in health care due to their ability to acquire multidrug resistance determinants. Although outbreaks of diseases in a hospital may also be caused by methicillin sensitive $S$. aureus (MSSA) (Kurlenda et al., 2009), MRSA infections are especially easily spread throughout a hospital and, without implementation of a special surveillance program with control procedures, a risk of an epidemy in such a hospital is high (Kurlenda et al., 2007).

\section{Staphylococcal chromosome cassette (SCCmec)}

SCCmec is a $21-67-\mathrm{kb}$ genetic element that is found in the chromosome of methicillin resistant $S$. aureus at a unique site designated attBscc, located near the origin of replication. attBscc is found in an open reading frame of unknown function, identified as $\operatorname{orf} X$, that is well conserved among $S$. aureus strains. The integration site of SCCmec, attBscc, contains a 15-bp sequence that, when SCCmec is inserted in the chromosome, is found at both chromosomeSCCmec junctions (attL and attR). However, unlike the direct repeats found in transposons, which are created by target duplication, one of the two repeat sequences is located within SCCmec at its right end. Degenerate inverted repeats are also present at both ends of SCCmec (Ito et al., 2001; Noto et al., 2008). These incomplete inverted repeats are thought to be recognized by SCCmec-specific recombinase during excision and integration of this element from and to chromosome (Fig. 1) (Hiramatsu et al., 2001; Noto et al., 2008).

SCCmec is a variable genetic element with certain conserved features. Among the conserved elements, SCCmec contains the mec operon composed of mecA and its regulatory genes, as well as the cassette chromosome recombinase complex ccr (Ito et al., 2001; 2004; Baba et al., 2002; Holden et al., 2004 ; Gill et al., 2005; Diep et al., 2006). The ccr locus is composed of the cassette chromosome recombinase genes, 


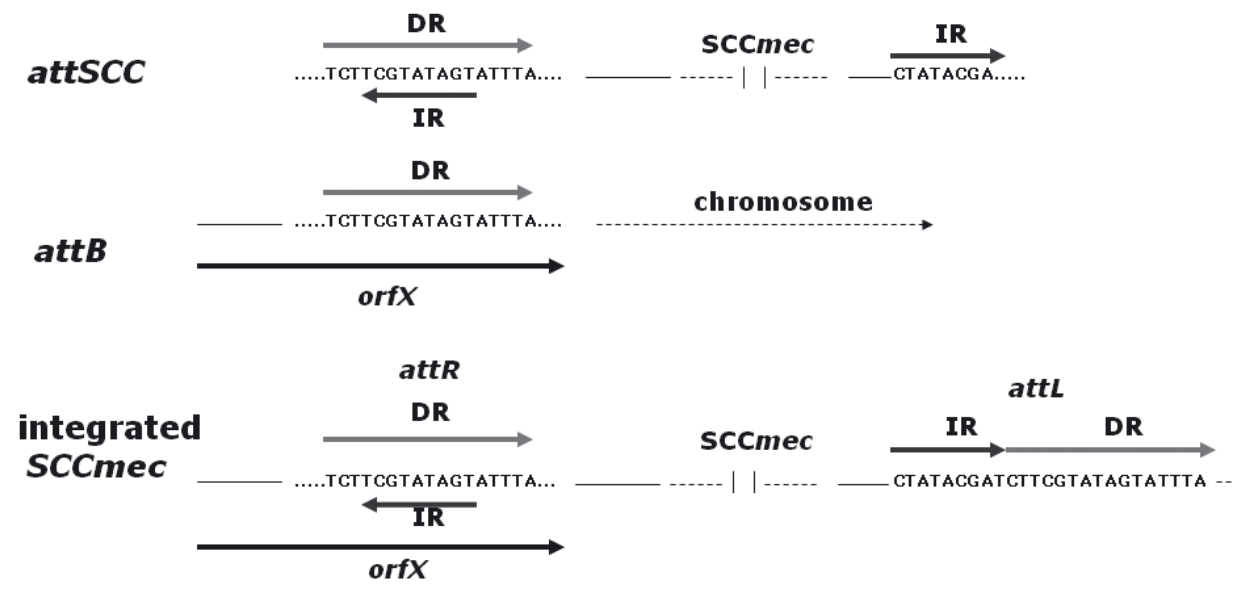

Figure 1. Schematic representation of attachment sites for SCCmec integration.

The SCCmec attachment site (attSCC) as it is found on the circular extra-chromosomal SCCmec elements (top panel). Chromosomal attachment site $(a t t B)$ located within $\operatorname{orfX}$ near origin of replication (middle panel). Integrated into chromosome, SCCmec with hybrid attachment sites at both ends (attL and attR) (bottom panel). Light-grey arrows indicate direct repeat sequences, dark-grey arrows - indirect repeat sequences, and black arrows - coding region of orf X (Noto et al., 2008).

$\operatorname{ccr} A, \operatorname{ccr} B$ or $\operatorname{ccr} C$, that are involved in the integration into the chromosome and in precise excision form the chromosome of the SCCmec element (Katayama et al., 2000; Ito et al., 2001; 2004). The variable regions of SCCmec, called J-region, contain integrated genetic elements such as plasmids (pT181, pUB110 and p1258), transposons (Tn554) and insertion sequences (IS431, IS1272 and IS256) (Hanssen \& Ericson Sollid, 2006).

The hallmark of SCCmec is the mec operon that consists of mecA and its regulatory genes mecI and mecR1 (Fig. 2). The operon is found in several variants as a component of different SCCmec elements. The variants of the mec operon are divided into two main categories: those with both mecI and mecR1 genes intact and those with portions of one or both of these regulatory genes deleted. The first group of the mec complex is known as class A mec operon while the latter have been categorized as classes B, C, D, E.

All classes of the mec operon include a copy of IS431 associated with the mecA gene and therefore designated IS431mec. Classes B-E contain deletions of mecI that may be extended to part of the mecR1 gene. Usually these deletions coincide with insertion of IS elements. Moreover, the $c c r$ locus of SCCmec elements also exists in several variants. As mentioned above, the

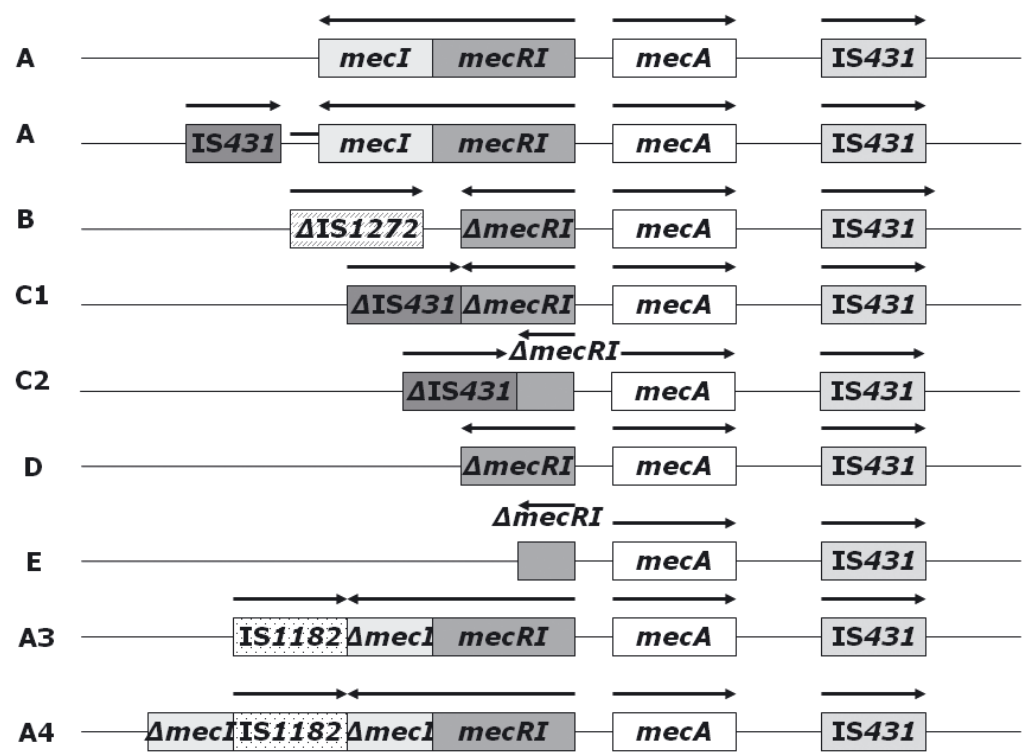

Figure 2. Structural classes of mec operon.

Direction of transcription is indicated by arrows above each element. Designation of each variant is shown on the left. After Hanssen and Ericson-Sollid (2006). 
Table 1. Characteristics of eight types of SCCmec elements.

(Based on: Hiramatsu et al., 2001; Deurenberg \& Stobberingh, 2008; Zhang et al., 2009)

\begin{tabular}{lllll}
\hline SCCmec type & mec complex & $c c r$ genes & Size & Other resistance determinants \\
\hline I & class B-E & $c c r A 1 B 1$ & $34 \mathrm{~kb}$ & None \\
II & class A & $c c r A 2 B 2$ & $52-58 \mathrm{~kb}$ & $\begin{array}{l}\text { Erythromycin, spectinomycin, bleomycin, } \\
\text { tetracycline }\end{array}$ \\
III & class A & $c c r A 3 B 3$ & $67 \mathrm{~kb}$ & $\begin{array}{l}\text { Erythromycin, spectinomycin, tetracycline, } \\
\text { mercury, cadmium }\end{array}$ \\
IV & class B-E & $\begin{array}{l}c r A 2 B 2 \text { or } \\
\text { ccrA4B4 }\end{array}$ & $20-25 \mathrm{~kb}$ & None \\
V & class B-E & $c r C$ & $28 \mathrm{~kb}$ & None \\
VI & class B & $c c r B 4$ & $20-25 \mathrm{~kb}$ & None \\
VII & class C & $c c r C 2, c c r C 8$ & $28-30 \mathrm{~kb}$ & None \\
VIII & class A & $c c r A 4, c c r B 4$ & $32 \mathrm{~kb}$ & Erythromycin, spectinomycin \\
\hline
\end{tabular}

$c c r$ locus contains either $c c r A$ and $c c r B$ or $c c r C$. Based on differences in nucleotide sequences, the combination $\operatorname{cr} A$ and $\operatorname{cr} B$ allotypes are divided into eight complexes of the $c c r$ gene (types I through VIII, Fig. 3) (Komatsuzawa et al., 1994; Katayama et al., 2001).

To date, at least five types of SCCmec elements have been defined based on combination of different mec (Fig. 2) and ccr (Table 1) complexes they contain. Table 1 describes the characteristics of the eight main SCCmec types.
Two PCR-based methods of SCCmec typing have been developed allowing characterization of this genetic element. Ito and coworkers (2001) established a method in which portions of the mec complex as well as specific parts of $c c r$ genes are amplified by means of PCR. Using this method SCCmec elements are typed according to the combination of the mec operon and $\mathrm{ccr}$ genes present. Oliveira and de Lancastre developed a multiplex PCR strategy that detects other regions of SCCmec in addition to

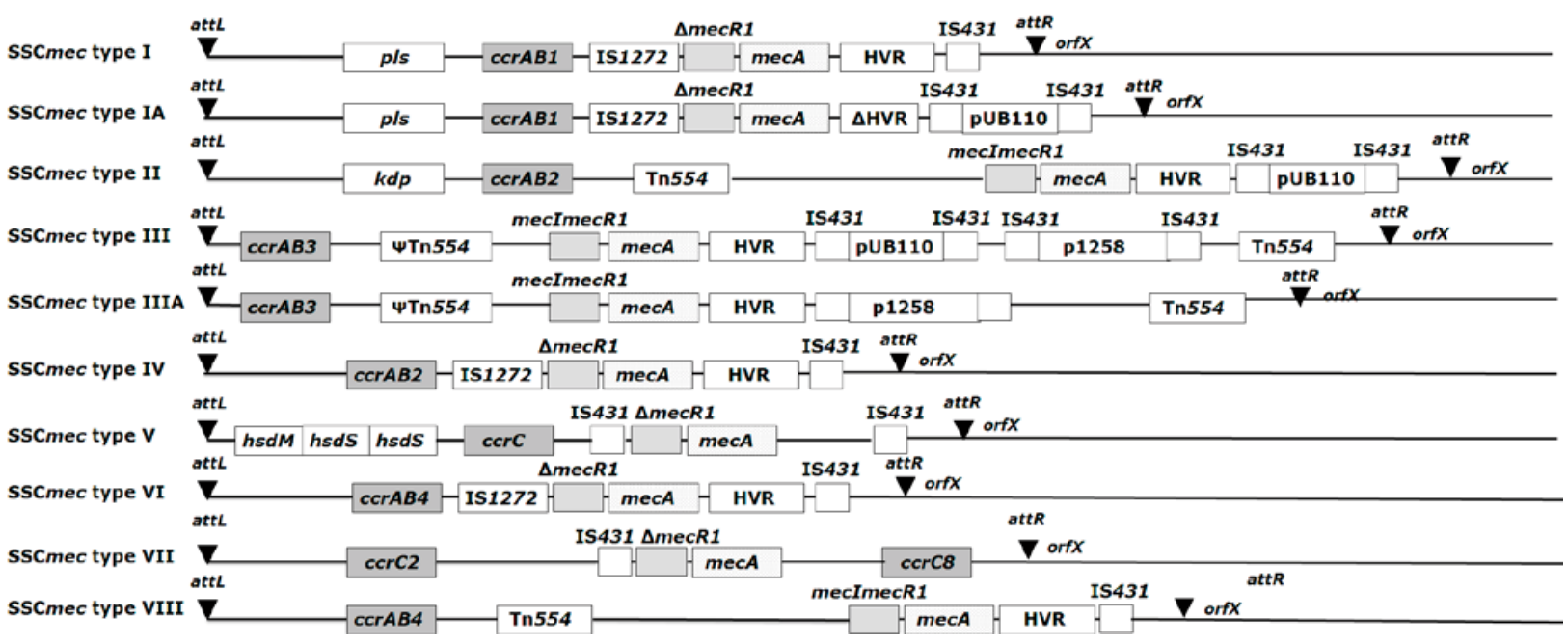

Figure 3. Schematic representation of SCCmec types I-VII and their variants.

Labels indicate names of genes, insertion sequences, transposons and plasmids, pls, plasmin sensitive surface protein; $k d p$, operon involved in ATP-dependent potassium transport; HVR, hypervariable region; ccrAB1, ccrAB2, ccrAB3, ccrC, allelic variants of SSCmec-specific recombinases; $h s d$, type I restriction-modification system; pUB110, pT181, pI258, integrated plasmids; Tn554, $\Psi$ Tn554, transposon and pseudo-transposon, respectively; IS431, IS1272, insertion sequences; mecl, mecRI, repressor and sensor, respectively, of the mec two-component system; mecA, low affinity penicillin binding protein. After Ito et al. (2001; 2004), Oliveira et al. (2001), Okuma et al. (2002), Hanssen and Ericson-Sollid (2006). 
the mec and $\mathrm{ccr}$ loci. This method allows detecting structural variants of SCCmec elements ( $\mathrm{Au}$ et al., 2005; Milheirico et al., 2007).

The first clinical isolates of MRSA were reported just one year after introduction of methicillin, and they were resistant to multiple antibiotics in addition to $\beta$-lactams. It was proposed that these strains had probably been selected by the common use of a variety of antibiotics in healthcare settings (Rice, 2006). The isolates were identified as MRSA SCCmec types I, II and III. The phenomenon of multi-resistance among these strains was largely due to the presence of particular SCCmec types I and II which contain integrated transposons and plasmids that carry additional resistance determinants. The copy of IS431 adjacent to the mecA gene and designated IS431mec is thought to facilitate the acquisition of resistance determinants through homologous recombination (e.g., plasmids pUB110 and pT181) (Katayama et al., 2000; Ito et al., 2001). Since 1990, several MRSA have been isolated as the pathogenic agents of severe infections in the community. These isolates caused disease among individuals without the typical factors for MRSA infections, such as recent hospitalization, admission in long term care facility or preexisting health problems. These community-acquired MRSA, designated CA-MRSA, were susceptible to many antibiotics other than $\beta$-lactams and contained the SCCmec type IV (Fey et al., 2003). Some CA-MRSA (USA300) contain a newly discovered mobile genetic element, arginine catabolic mobile element (ACME). The physical linkage between SCCmec and ACME suggests that selection for antibiotic resistance and for pathogenicity may be interconnected (Diep et al., 2008). Another variant of pathogenic CA-MRSA strain was isolated which contains type V SCCmec (Ito et al., 2004). Recently, nevely discovered types of SCCmec, designated types VI, VII and VIII, have been described (Deurenberg \& Stobberingh, 2008; 2009; Zhang et al., 2009).

SCCmec contains many open reading frames exhibiting atypical codon usage and skewed $\mathrm{G}+\mathrm{C}$ content at the third codon positions indicating that this genetic element was acquired by $S$. aureus relatively recently from another species (Kuroda et al., 2001). The origin of SCCmec and the mechanism of transfer are unknown. A possible evolutionary precursor of the mecA gene of MRSA strains, exhibiting $88 \%$ identity, was found in S. sciuri (Wu et al., 2001). It has been proposed that the $\mathrm{ccr}$ and the mec genes were brought together in coagulase-negative staphylococci where deletions in the mec regulatory genes occurred before the transfer to $S$. aureus. There is also evidence supporting the hypothesis of SCCmec transfer from coagulase-negative staphylococci to S. aureus. The IS1272 element is found in intact form and in multiple copies in the genome of $S$. haemolyticus, whereas it typically contains deletions in S. aureus and S. epidermidis. This suggests that $S$. haemolyticus was the primary host of this element and it was secondarily acquired by $S$. aureus and S. epidermidis by means of horizontal transfer (Kobayashi et al., 1999). There is also report of in vivo MRSA formation by horizontal transfer of mecA between S. epidermidis and S. aureus during antibiotic therapy (Wielders et al., 2001). Methicillin resistance is common in S. epidermidis (more than $70 \%$ hospital isolates) and is less common among S. aureus strains. The presence of SCCmec type IV (Fig. 3) was common among S. epidermidis isolates from the 1970s and was not reported in methicillin resistant $S$. aureus strains during that time. The rapid emergence and dissemination of community-acquired MRSA containing SCCmec type IV lead to the hypothesis that $S$. epidermidis may act as a reservoir of SCCmec type IV in the community and the recurring transfer of this element into methicillin sensitive S. aureus (MSSA) is partly responsible for the increasing occurrence of CA-MRSA (Wisplinghoff et al., 2003). It has been proposed that recombination between SCCmec type I and other sequences occurred in coagulase-negative staphylococci leading to the generation of SCCmec type IV which was subsequently transferred to $S$. aureus (Wisplinghoff et al., 2003). This data supports the hypothesis that SCCmec are mobile genetic elements in the environment and their transfer into methicillin sensitive $S$. aureus contributes to the spread of MRSA. It has been estimated that $S$. aureus has acquired SCCmec element at least in 20 independent occasions (Robinson \& Enright, 2003; Deurenberg et al., 2007). Hospital-acquired MRSA (HA-MRSA) infections historically have been caused by internationally dispersed clones, including five major ones (the Iberian, Brazilian, Hungarian, New York/Japan and Pediatric). These multi-drug resistant clones are disseminated globally and account for the majority of HA-MRSA infections. However, it remains unclear why particular clones are more successful in becoming the established "HA-MRSA" in certain regions (Robinson \& Enright, 2003).

\section{Cell wall structure and biosynthesis}

The staphylococcal cell wall is a dynamic, semi-rigid structure. It is composed of three components: peptidoglycan, teichoic acids and surface proteins. Of these three constituents, peptidoglycan is the major component which builds the murein sacculus. Structurally, peptidoglycan forms a macromolecular net in which glycan strands are cross-linked by short peptides. The glycan strands are composed of repeating disaccharide units of $\beta-1-4$ linked $N$ acetylglucosamine and $\mathrm{N}$-acetylmuramic acid (Labischinski, 1992). The majority of glycan chains have a length of 3-10 disaccharide units. Extending from the carboxyl residue of the $\beta-1-4$ linked acetylglucos- 
amine moiety is the stem peptide with the sequence: L-alanyl-D-isoglutaminyl-L-lysyl-D-alanyl-D-alanine (Scheffers \& Pinho, 2005). A series of five L-glycine residues are attached to the L-lysine of the stem peptide which is a characteristic feature of the $S$. aureus cell wall. The pentaglycine cross-bridge is synthesized in a sequential manner by a family of FemABX non-ribosomal peptide transferases (Berger-Bachi \& Tschierske, 1998; Rohrer et al., 2003).

The first step of peptidoglycan synthesis takes place in the cytoplasm and leads to the synthesis of nucleotide sugar-linked precursors: UDP-N-acetylmuramyl-pentapetide (UDP-murNAc-pentapeptide) and UDP-N-acetylglucosamine (UDP-GlcNAc). In the second stage, which occurs at the cytoplasmic membrane, UDP-murNAc-pentapeptide is transferred to the membrane-bound acceptor (bactoprenol) yielding lipid I and is followed by addition of UDP-GlcNAc resulting in lipid II formation. Bactoprenol (undecaprenol phosphate) is a lipophilic molecule that enables the cell to translocate hydrophilic precursors from the aqueous cytoplasm across the hydrophobic membrane to the externally localized sites of polymerization of peptidoglycan (Scheffers \& Pinho, 2005; Bouhss et al., 2008).

The final step of biosynthesis takes place outside the cytoplasmic membrane and involves incorporation of the recently synthesized disaccharide-peptide units into the peptidoglycan. The last step of peptidoglycan synthesis is carried out by penicillin-binding proteins (PBPs) which catalyze the transglycosylation and transpeptidation reactions, i.e., formation of the glycosidic and peptide bonds, respectively.

The transglycosylation is catalyzed by multimodular penicillin-binding proteins, particularly PBP2 and by the monofunctional glycosyltransferase, Mtg, and results in incorporation of the lipid- linked precursors into the glycan polymer (Wang et al., 2001; Barrett et al., 2005). In the transpeptidation (cross-linking) reaction, which is also catalyzed by PBPs, the terminal L-glycine of the pentaglycine interpeptide bound to L-lysine of one stem peptide is attached to the D-alanine of another stem peptide. The terminal D-alanine of this stem peptide is cleaved off during this reaction. Thus, a flexible pentaglycine cross-bridge is formed between two peptidoglycan moieties, resulting in a strong and flexible cell wall structure (Gally \& Archibald, 1993). S. aureus typically possesses four PBPs which are able to catalyze the transpeptidation reaction. PBPs 1, 2 and 3 are high molecular mass proteins (87, 80 and $75 \mathrm{kDa}$, respectively) and PBP4 is a low molecular mass protein $(41 \mathrm{kDa})$. Figure 4 depicts the cell wall structure as well as the transglycosylation and transpeptidation reactions (Scheffers \& Pinho, 2005).

Another component of the $S$. aureus cell wall are teichoic acids, which are polymers of ribitol residues or polymers of glycerol phosphate. Teichoic acids contribute to the negative charge present on the cell surface that plays a role in acquisition of ions, also and have been reported to be a component of S. aureus phage receptor (Chatterjee, 1969).

The last component of the $S$. aureus cell wall are surface proteins, including microbial surface components recognizing adhesive molecules (MSCRAMMs). These proteins contain a signal sequence directing their secretion and the LPXTG motif. The LPXTG motif is cleaved by sortase and than the proteins are covalently attached to the peptidoglycan. Protein A, fibronectin binding protein, collagen binding protein and clumping factor $\mathrm{A}$, among many others, are components of the cell wall and are attached in this manner (Foster \& Hook, 1998).

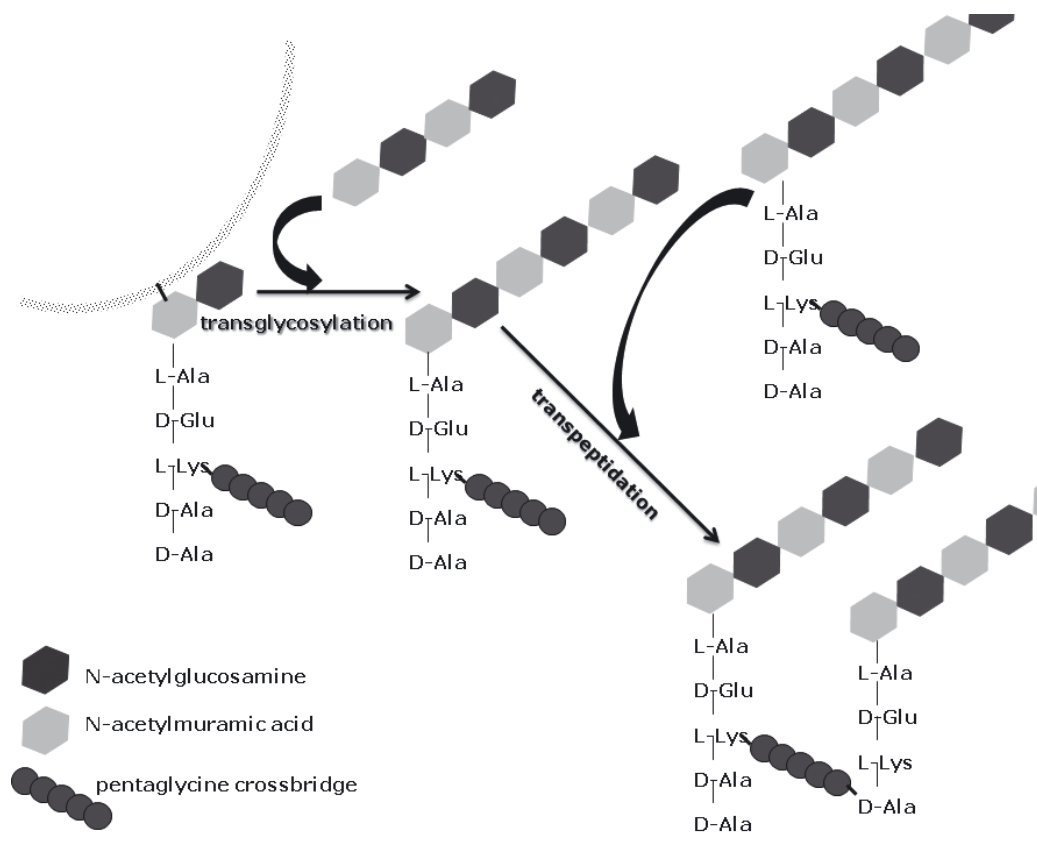

Figure 4. Scheme of staphylococcal peptidoglycan biosynthesis.

Transglycosylation and transpeptidation reactions catalyzed by penicillin binding proteins are shown. Stem peptides and cross-bridges are not shown on all $\mathrm{N}$-acetylmuramic acid residues of the glycan chains. Modified after (Scheffers \& Pinho, 2005; Vollmer et al., 2008). 
Mechanism of $\beta$-lactams antibiotic action

$\beta$-Lactam antibiotics include penicillins, cephalosporins, and penicillinase-insensitive $\beta$-Lactams such as methicillin and oxacillin. $\beta$-Lactams are bactericidal, cell wall-active agents that target the transpeptidation step of the peptidoglycan synthesis. This is achieved by binding and inactivating the transpeptidase domain of PBPs in the cell wall (Chambers, 2004). $\beta$-Lactams are structural analogs of the natural substrate of PBPs, D-alanyl-D-alanine of the peptidoglycan stem peptide (Fig. 5).

The reaction between PBP and a $\beta$-lactam antibiotic begins with a non-covalent association between these two molecules. This intermediate can either dissociate or undergo an irreversible reaction of acylation, when the PBP covalently binds the antibiotic at its active site, cleaving the cyclic amide bond in the $\beta$-lactam ring. The natural substrate for PBP, D-alanyl-D-alanine, undergoes quick deacylation by hydrolysis that liberates the PBP for a next round of transpeptidation. However, when the substrate is a $\beta$-lactam antibiotic, the deacetylation process is very slow and the PBP is effectively inactivated. Without functional PBPs, the cell wall synthesis is inhibited and cell death occurs (Chambers, 2003). The features of $\beta$-lactams which make them attractive antimicrobial agents stem from the fact that their targets are easily accessible (localized outside of the cytoplasm membrane) and that they are specific to bacteria (lacking functional and structural equivalents in the human organism) (Wilke et al., 2005).

\section{Mechanism of resistance: $\beta$-lactamases}

$\beta$-Lactamases are proteins with enzymatic activities that contribute to $\beta$-lactam resistance by inactivation of many of these antibiotics in a reaction similar to the one $\beta$-lactams use to inhibit PBPs. $\beta$-Lactamases bind $\beta$-lactams, which results in formation of an acylated intermediate. Unlike the reaction catalyzed by PBPs during peptidoglycan biosynthesis, resolution of the acylated intermediate results in the cleavage of the amide bond of the $\beta$-lactam ring. The inactivated $\beta$-lactam antibiotic and active $\beta$-lactamase are released (Frere, 1995). Based on sequence similarity four different types of $\beta$-lactamases have been described so far in $S$. aureus which differ in their substrate specificity (Zygmunt et al., 1992).

The gene coding for $\beta$-lactamase (blaZ) is usually carried on a plasmid or located on a transposon. Expression of $\beta$-lactamase is induced by the presence of $\beta$-lactam antibiotics through a regulatory system composed of a repressor, BlaI, and a signal transducer, BlaRI. Genes blaI and blaRI are located a in two-gene operon that is divergently transcribed from blaZ. BlaRI is a membrane protein composed
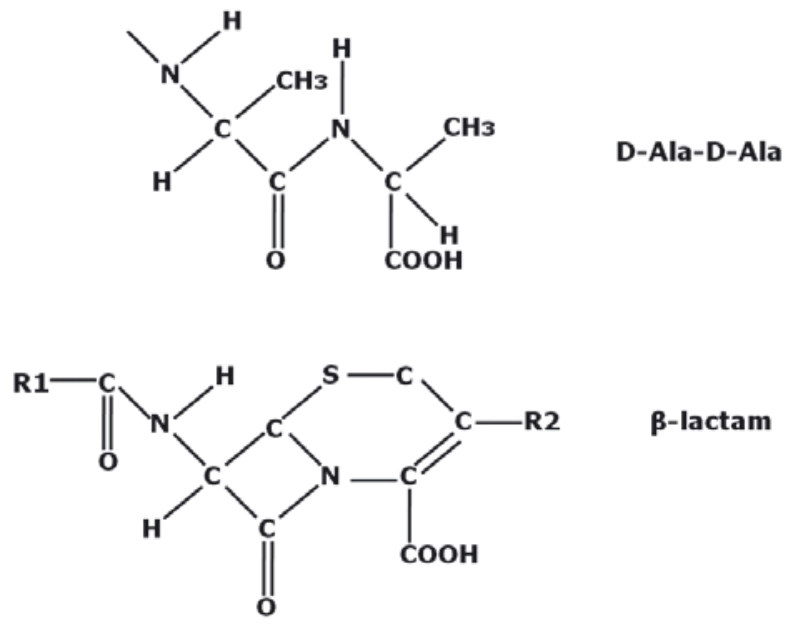

Figure 5. Structures of D-alanyl-D-alanine and a $\beta$-lactam antibiotic.

$\beta$-Lactams and D-Ala-D-Ala have similar structures that allow them to be bound by PBPs. R1 and R2 indicate groups that differ among various $\beta$-lactam antibiotics.

of an extracellular sensor domain that is acylated by $\beta$-lactam antibiotics, a membrane-spanning domain that transduces the signal across the membrane, and an intracellular zinc metalloprotease domain which is proteolytically activated upon acylation of the sensor domain. BlaI repressor forms a homodimer which binds to the operator region of the operon encoding BlaI and BlaRI and containing the $\beta$-lactamase structural gene (blaZ). Upon binding of a $\beta$-lactam antibiotic to the sensor domain of BlaRI, its metalloprotease domain undergoes autocleavage and subsequent cleavage of BlaI, which prevents its dimerization, operator binding and leads to derepression of blaZ transcription (Zhang et al., 2001).

\section{Mechanism of resistance: methicillin resistance}

Methicillin, oxacillin and nafcillin are semisynthetic $\beta$-lactamase-insensitive $\beta$-lactams. S. aureus has developed resistance to this class of $\beta$-lactams by acquiring the mecA gene carried on the SCCmec element described above. Strains containing mecA are known as methicillin resistant $S$. aureus (MRSA), although they are, in fact, resistant to all $\beta$-lactam antibiotics (Berger-Bachi, 1994; Chambers, 1997; 2003). mec $A$ encodes an alternative penicillin binding protein PBP2a, that has low affinity for $\beta$-lactams. PBP2a belongs to the group of high molecular mass (78 kDa) family of PBPs and consists of a transpeptidase domain and a non-penicillin binding domain of unknown function (Goffin \& Ghuysen, 1998). PBP2a is known to posses low affinity for $\beta$-lactams that allows MRSA strains to grow in antibiotic concentrations that inactivate all native PBPs (Gaisford \& Reynolds, 1989). PBP2a appears to be a rather poorly active enzyme, comparing to other native PBPs 
that synthesize highly cross-linked peptidoglycan (de Jonge \& Tomasz, 1993). Even when the transpeptidase activity of all native PBPs is inhibited by the presence of methicillin, PBP2a has been shown to rely on the transglycosylase, $\beta$-lactam-insensitive, domain of the native PBP2 to confer resistance (Pinho et al., 2001).

The serine in the active site of the transpeptidase domain in PBP2a is responsible for nucleophilic attack on both the $\beta$-lactam ring and the D-alanyl-D-alanine substrate and is located in an extended narrow groove. The groove mediates noncovalent interactions with the $\beta$-lactam that place the $\beta$-lactam in an unfavorable position for interaction with the serine in the active site. As a result, the acylation between the $\beta$-lactam and the active site does not occur. PBP2a successfully balances the crucial transpeptidase activity with a decreased affinity toward $\beta$-lactam antibiotics. Therefore PBP2a is able to synthesize the cell wall at otherwise lethal concentrations of $\beta$-lactams (Pinho et al., 2001; Lim \& Strynadka, 2002; Chambers, 2003).

\section{Regulation of mecA expression}

The expression of the mecA gene is regulated in analogous manner to that of the $\beta$-lactamase gene, blaZ. Similarly to blaZ, mecA is divergently transcribed from its two regulatory genes organized in an operon, mecI and mecR1. Homodimeric methicillin repressor, MecI, constitutively represses expression of mecA as well as transcription of the mecl-mecRI operon by binding to two palindromes contained within the promoter-operator region (Safo et al., 2006). Derepression occurs through cleavage of MecI upon activation of the metalloprotease domain of the mecRI sensor-transducer by a $\beta$-lactam antibiotic.

MecRI is a membrane protein that has an extracellular penicillin-binding domain that, when bound by $\beta$-lactams, undergoes a conformational change inducing autocleavage of the intracellular protease domain. The active MecRI cleaves MecI which leads to derepression of mecA as well as the mecI-mecRI operon (Mallorqui-Fernandez et al., 2004). Additionally to regulation of mecA expression by its cognate MecI and MecRI regulators, it can also be regulated by structurally and functionally similar $\beta$-lactamase regulators, BlaI and BlaRI. Because of the structural and functional similarity, MecI as well as BlaI are able to bind as homodimers to the promoter-operator region of mecA (Gregory et al., 1997). The MecI or BlaI-mediated repression is only relieved by induction through homologous, and not heterologous sensor-transducers, demonstrating the repressor specificity of induction. Induction of mec $A$ expression by the MecRI-MecI system is slower than

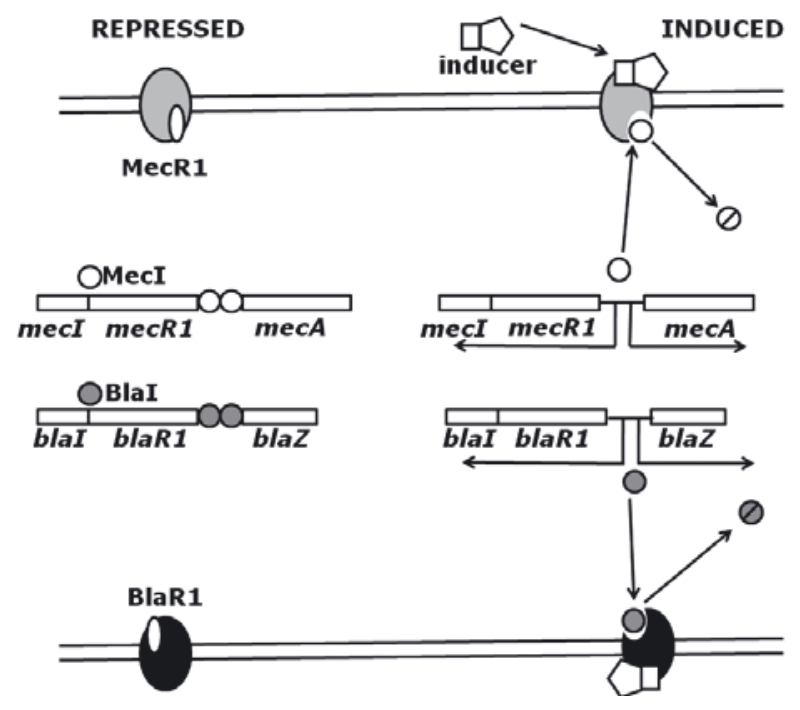

Figure 6. Two pathways regulating PBP2a and $\beta$-lactamase production.

MecI represses transcription of mecA and mecRI-mecI operon. Upon binding of $\beta$-lactam to sensor domain of MecRI, intracellular peptidase domain cleaves MecI repressor, which triggers mecA and mecI transcription. Analogous system controls blaZ and blaRI-blaI expression. Despite BlaI and MecI repressors are being interchangeable and both recognizing mec and bla regulatory sequences, cleavage of the expression regulators by BlaRI and MecRI is specific. Adapted form Berger-Bachi and Rohrer (2002).

the induction by BlaRI-BlaI and never leads to maximal mecA transcription (Potempa et al., 1991). Figure 6 shows the regulation of mec $A$ and blaZ expression.

Repression of mecA by MecI and BlaI is even stronger if these two repressors are present together (Rosato et al., 2003a). The majority of clinical MRSA strains contain mutations in mecl, however, in the vast majority of these cases, mecA expression is commonly regulated by BlaI. This highlights the need of controlled transcription of mecA by at least one of the two regulators. Given the more rapid rate of induction through BlaRI-BlaI, it has been proposed that it might be the preferred system of mecA regulation (Rosato et al., 2003b). In so called pre-MRSA strains, carrying both functional regulatory systems, mec $A$ expression is controlled by both MecI and BlaI. This strict repression can prevent mec $A$ transcription, and thus cause inhibition of $\beta$-lactam resistance, leading to the misinterpretation of these isolates as methicillin sensitive $S$. aureus (MSSA) (Niemeyer et al., 1996; Weller, 1999). It has also been shown that certain genetic backgrounds of MSSA strains carrying plasmid-borne, unregulated mec $A$ are restrictive and select against mecA expression because mecA is often mutated or deleted to avoid production of PBP2a in such strains. However, when the mec or bla regulatory genes are introduced together with mecA, 
the system is tolerated. These findings emphasize not only the importance of tight regulation of mecA expression but also the influence of particular genetic backgrounds on mecA stability and the resistance phenotype (Katayama et al., 2005).

At present, MRSA infections have a higher frequency than methicillin-susceptible $S$. aureus (MSSA) infections in some settings. MRSA was accountable for $59 \%$ of skin and soft tissue infections diagnosed in eleven emergency departments in the United States (Okuma et al., 2002). Moreover, MRSA accounted for $59.5 \%$ of all $S$. aureus infections in intensive care units patients in 2004 (Rice, 2006). Also, the occurrence of MRSA infections outside healthcare facilities, in the community, more than doubled between 2002 and 2004. The increasing rate of MRSA infections has shifted chemotherapy away from $\beta$ lactam antibiotics toward antibiotics more effective against MRSA, such as vancomycin and daptomycin (Berger-Bachi et al., 1992).

\section{Heterogeneous and homogeneous methicillin resistance}

The level of methicillin resistance of $S$. aureus varies extremely from one strain to another, spanning the range from several micrograms per milliliter (a value very close to the resistance level of MSSA) to several milligrams pre milliliter. Certain MRSA strains are composed of cells expressing varied levels of resistance to $\beta$-lactams. They are apparently made up of several bacterial sub-populations that significantly differ in their degree of antibiotic resistance. This peculiar non-consistency in the phenotypic expression of antibiotic resistance is called heteroresistance (Tomasz et al., 1991).

Heterogeneous expression of methicillin resistance is characterized by a majority of cells expressing low level resistance from which, upon challenge with methicillin, a small proportion of highly, uniformly resistant clones segregate. The frequency of segregation of the highly resistant sub-clones designated homoresistant is a reproducible and straindependent property. The homoresistant phenotype is stable and the highly resistant clones generally maintain their resistance level even in the absence of selective pressure (Berger-Bachi \& Rohrer, 2002). The ability of MRSA strains to produce PBP2a is essential for their methicillin resistance but there is no correlation between homo- and heteroresistance and the cellular concentration of PBP2a. PBP2a production does not seem to explain the observed variety of resistance levels. Therefore it is thought that additional chromosomal genes are involved in optimal methicillin resistance (Hackbarth et al., 1994; Murakami \& Tomasz, 1989). It has been proposed that selection of a homoresistant derivative from a heteroresistant population is due to unspecified mutations or genetic rearrangements occurring outside the SCCmec element. However, the size of the homoresistant subpopulation selected upon challenge with oxacillin is well above the frequency of spontaneous mutations (Finan et al., 2002).

The same mechanism of selection of a highly homoresistant subpopulation from a heteroresistant population is thought to operate in clinical environments and it could be blamed for the failure of $\beta$ lactam treatment against MRSA (Berger-Bachi, 1999). Moreover, very low-level resistant MRSA strains are dangerous since they can evade standard phenotypic detection while they appear phenotypically susceptible. These strains still carry the mecA determinant and express resistance heterogeneously and upon $\beta$-lactam exposure they are able to segregate highly resistant subpopulations at a frequency well above spontaneous mutation rate (Ender et al., 2008).

\section{CONCLUDING REMARKS}

Although it is estimated that approximately $20-30 \%$ of the general human population are "healthy" S. aureus carriers, this bacterium can also be a serious infectious agent responsible for relatively frequent and severe diseases. Particularly MRSA strains are dangerous due to their resistance to most antibiotics currently used in clinical practice. A better understanding of the biochemical and genetic mechanisms of $S$. aureus pathogenicity will lead to improved prevention and treatment strategies. Nevertheless, although various approaches are being considered, including special procedures of antibiotic treatment, photodynamic therapy or bacteriophage therapy (see, for example: Dzwonkowska et al., 2007; Grinholc et al., 2008; Jurczak et al., 2008; Mann, 2008; Grinholc et al. 2008), it appears to be a formidable task.

\section{Acknowledgments}

This work was supported by award 1K22AI057724-01A1 from the National Institute of Allergy and Infectious Diseases (to AER), by the Department of Internal Medicine, Virginia Commonwealth University (funds to AER), and by the Department of Molecular Biology, University of Gdansk (funds to GW).

\section{REFERENCE}

Arciola CR, Baldassarri L, Montanaro L (2001a) Presence of icaA and icaD genes and slime production in a collection of staphylococcal strains from catheter-associated infections. J Clin Microbiol 39: 2151-2156. 
Arciola CR, Campoccia D, Borrelli AM, Donati ME, Montanaro L (2001b) Congo red agar plate method: improved accuracy and new extended application to Staphylococcus aureus. New Microbiol 24: 355-363.

Baba T, Takeuchi F, Kuroda M, Yuzawa H, Aoki K, Oguchi A et al. (2002) Genome and virulence determinants of high virulence community-acquired MRSA. Lancet 359: 1819-1827.

Baba T, Takeuchi F, Kuroda M, Ito T, Yuzawa H, Hiramatsu K (2004) The Staphylococcus aureus genome. Harwood Publishing Limited, West Sussex, England.

Baker MD, Acharya KR (2004) Superantigens: structurefunction relationships. Int J Med Microbiol 293: 529-537.

Barrett D, Leimkuhler C, Chen L, Walker D, Kahne D, Walker S (2005) Kinetic characterization of the glycosyltransferase module of Staphylococcus aureus PBP2. J Bacteriol 187: 2215-2217.

Bates DM, von Eiff C, McNamara PJ, Peters G, Yeaman MR, Bayer AS, Proctor RA (2003) Staphylococcus aureus menD and hemB mutants are as infective as the parent strains but the menadione biosynthetic mutant persists within the kidney. I Infect Dis 187: 1654-1661.

Berger-Bachi B (1994) Expression of resistance to methicillin. Trends Microbiol 2: 389-393.

Berger-Bachi B (1999) Genetic basis of methicillin resistance in Staphylococcus aureus. Cell Mol Life Sci 56: 764-770.

Berger-Bachi B, Rohrer S (2002) Factors influencing methicillin resistance in staphylococci. Arch Microbiol 178: 165-171.

Berger-Bachi B, Strassle A, Gustafson JE, Kayser FH (1992) Mapping and characterization of multiple chromosomal factors involved in methicillin resistance in Staphylococcus aureus. Antimicrob Agents Chemother 36: 1367-1373.

Berger-Bachi B, Tschierske M (1998) Role of fem factors in methicillin resistance. Drug Resist Updat 1: 325-335.

Boisset S, Geissmann T, Huntzinger E, Fechter P, Bendridi N, Possedko M et al. (2007) Staphylococcus aureus RNAIII coordinately represses the synthesis of virulence factors and the transcription regulator Rot by an antisense mechanism. Genes Dev 21: 1353-1366.

Bouhss A, Trunkfield AE, Bugg TD, Mengin-Lecreulx D (2008) The biosynthesis of peptidoglycan lipid-linked intermediates. FEMS Microbiol Rev 32: 208-233.

Chambers HF (1997) Methicillin resistance in staphylococci: molecular and biochemical basis and clinical implications. Clin Microbiol Rev 10: 781-791.

Chambers HF (2003) Solving staphylococcal resistance to beta-lactams. Trends Microbiol 11: 145-148.

Chambers HF (2004) Antimicrobial resistance and therapy. In Staphylococcus aureus Molecular and Clinical Aspects. Harwood Publisher Limited, West Sussex, England.

Chatterjee AN (1969) Use of bacteriophage-resistant mutants to study the nature of the bacteriophage receptor site of Staphylococcus aureus. J Bacteriol 98: 519-527.

Clements MO, Watson SP, Poole RK, Foster SJ (1999) CtaA of Staphylococcus aureus is required for starvation survival recovery cytochrome biosynthesis. J Bacteriol 181: 501-507.

Crossley KB, Archer GL (1997) The Staphylococci in human disease. Churchill Livingstone.

de Jonge BL, Tomasz A (1993) Abnormal peptidoglycan produced in a methicillin-resistant strain of Staphylococcus aureus grown in the presence of methicillin: functional role for penicillin-binding protein 2A in cell wall synthesis. Antimicrob Agents Chemother 37: 342-346.

Deurenberg RH, Stobberingh EE (2008) The evolution of Staphylococcus aureus. Infect Genet Evol 8: 747-763.

Deurenberg RH, Stobberingh EE (2009) The molecular evolution of hospital- and community-associated methi- cillin-resistant Staphylococcus aureus. Curr Mol Med 9: 100-115.

Deurenberg RH, Vink C, Kalenic S, Friedrich AW, Bruggeman CA, Stobberingh EE (2007) The molecular evolution of methicillin-resistant Staphylococcus aureus. Clin Microbiol Infect 13: 222-235.

Diekema DJ, Pfaller MA, Schmitz FJ, Smayevsky J, Bell J, Jones RN, Beach M (2001) Survey of infections due to Staphylococcus species: frequency of occurrence and antimicrobial susceptibility of isolates collected in the United States, Canada, Latin America, Europe, the Western Pacific region for the SENTRY Antimicrobial Surveillance Program 1997-1999. Clin Infect Dis 32 (Suppl 2): S114-S132.

Diep BA, Gill SR, Chang RF, Phan TH, Chen JH, Davidson MG et al. (2006) Complete genome sequence of USA300 an epidemic clone of community-acquired meticillin-resistant Staphylococcus aureus. Lancet 367: 731-739.

Diep BA, Stone GG, Basuino L, Graber CJ, Miller A, des Etages SA et al. (2008) The arginine catabolic mobile element and staphylococcal chromosomal cassette mec linkage: convergence of virulence and resistance in the USA300 clone of methicillin-resistant Staphylococcus aureus. J Infect Dis 197: 1523-1530.

Dzwonkowska J, Kurlenda J, Baczkowski B, Mazurkiewicz S, Uzunov I, Ziolkowski W, Markowicz A (2007) The effect of antibiotic therapy on the incidence of Staphylococcus aureus infections in orthopaedic patients. Ortop Traumatol Rehabil 9: 532-547.

Ender M, McCallum N, Berger-Bächi B (2008) Impact of mecA promoter mutations on mecA expression and beta-lactam resistance levels. Int J Med Microbiol 298: 607-617.

Fey PD, Said-Salim B, Rupp ME, Hinrichs SH, Boxrud DJ, Davis CC et al. (2003) Comparative molecular analysis of community- or hospital-acquired methicillin-resistant Staphylococcus aureus. Antimicrob Agents Chemother 47: 196-203.

Finan JE, Rosato AE, Dickinson TM, Ko D, Archer GL (2002) Conversion of oxacillin-resistant staphylococci from heterotypic to homotypic resistance expression. Antimicrob Agents Chemother 46: 24-30.

Fitzpatrick F, Humphreys H, O'Gara JP (2005) The genetics of staphylococcal biofilm formation - will a greater understanding of pathogenesis lead to better management of device-related infection? Clin Microbiol Infect 11: 967-973.

Foster TJ (2005) Immune evasion by staphylococci. Nat Rev Microbiol 3: 948-958.

Foster TJ, Hook M (1998) Surface protein adhesins of Staphylococcus aureus. Trends Microbiol 6: 484-488.

Frere JM (1995) Beta-lactamases and bacterial resistance to antibiotics. Mol Microbiol 16: 385-395.

Gaisford WC, Reynolds PE (1989) Methicillin resistance in Staphylococcus epidermidis. Relationship between the additional penicillin-binding protein and an attachment transpeptidase. Eur J Biochem 185: 211-218.

Gally D, Archibald AR (1993) Cell wall assembly in Staphylococcus aureus: proposed absence of secondary crosslinking reactions. J Gen Microbiol 139: 1907-1913.

Gill SR, Fouts DE, Archer GL, Mongodin EF, Deboy RT, Ravel J et al. (2005) Insights on evolution of virulence and resistance from the complete genome analysis of an early methicillin-resistant Staphylococcus aureus strain and a biofilm-producing methicillin-resistant Staphylococcus epidermidis strain. J Bacteriol 187: 2426-2438.

Goffin C, Ghuysen JM (1998) Multimodular penicillinbinding proteins: an enigmatic family of orthologs and paralogs. Microbiol Mol Biol Rev 62: 1079-1093. 
Gordon RJ, Lowy FD (2008) Pathogenesis of methicillin-resistant Staphylococcus aureus infection. Clin Infect Dis $\mathbf{4 6}$ (Suppl 5): S350-S359.

Gregory PD, Lewis RA, Curnock SP, Dyke KG (1997) Studies of the repressor (BlaI) of beta-lactamase synthesis in Staphylococcus aureus. Mol Microbiol 24: 1025-1037.

Grinholc M, Wegrzyn G, Kurlenda J (2007) Evaluation of biofilm production and prevalence of the icaD gene in methicillin-resistant and methicillin-susceptible Staphylococcus aureus strains isolated from patients with nosocomial infections and carriers. FEMS Immunol Med Microbiol 50: 375-379.

Grinholc M, Kawiak A, Kurlenda J, Graczyk A, Bielawski KP (2008) Photodynamic effect of protoporphyrin diarginate (PPArg2) on methicillin-resistant Staphylococcus aureus and human dermal fibroblasts. Acta Biochim Polon 55: 85-90.

Hackbarth CJ, Miick C, Chambers HF (1994) Altered production of penicillin-binding protein 2 a can affect phenotypic expression of methicillin resistance in Staphylococcus aureus. Antimicrob Agents Chemother 38: 25682571.

Hanssen AM, Ericson Sollid JU (2006) SCCmec in staphylococci: genes on the move. FEMS Immunol Med Microbiol 46: 8-20.

Hartleib J, Kohler N, Dickinson RB, Chhatwal GS, Sixma JJ, Hartford OM et al. (2000) Protein A is the von Willebrand factor binding protein on Staphylococcus aureus. Blood 96: 2149-2156.

Hauck CR, Ohlsen K (2006) Sticky connections: extracellular matrix protein recognition and integrin-mediated cellular invasion by Staphylococcus aureus. Curr Opin Microbiol 9: 5-11.

Heyman D (2004) Control of Communicable Diseases Manual. 18th edn. American Public Health Association, Washington DC.

Hiramatsu K, Cui L, Kuroda M, Ito T (2001) The emergence and evolution of methicillin-resistant Staphylococcus aureus. Trends Microbiol 9: 486-493.

Holden MT, Feil EJ, Lindsay JA, Peacock SJ, Day NP, Enright MC et al. (2004) Complete genomes of two clinical Staphylococcus aureus strains: evidence for the rapid evolution of virulence and drug resistance. Proc Natl Acad Sci USA 101: 9786-9791.

Ito T, Katayama Y, Hiramatsu K (1999) Cloning and nucleotide sequence determination of the entire mec DNA of pre-methicillin-resistant Staphylococcus aureus N315. Antimicrob Agents Chemother 43: 1449-1458.

Ito T, Katayama Y, Asada K, Mori N, Tsutsumimoto K, Tiensasitorn C, Hiramatsu K (2001) Structural comparison of three types of staphylococcal cassette chromosome mec integrated in the chromosome in methicillinresistant Staphylococcus aureus. Antimicrob Agents Chemother 45: 1323-1336.

Ito T, Ma XX, Takeuchi F, Okuma K, Yuzawa H, Hiramatsu K (2004) Novel type V staphylococcal cassette chromosome mec driven by a novel cassette chromosome recombinase ccrC. Antimicrob Agents Chemother 48: 2637-2651.

Janzon L, Arvidson S (1990) The role of the delta-lysin gene (hld) in the regulation of virulence genes by the accessory gene regulator (agr) in Staphylococcus aureus. EMBO J 9: 1391-1399.

Jurczak A, Szramka B, Grinholc M, Legendziewicz J, Bielawski KP (2008) Photodynamic effect of lanthanide derivatives of meso-tetra( $N$-methyl-4-pyridyl)porphine against Staphylococcus aureus. Acta Biochim Polon 55: 581-585.
Kaneko J, Kamio Y (2004) Bacterial two-component and hetero-heptameric pore-forming cytolytic toxins: structures pore-forming mechanism organization of the genes. Biosci Biotechnol Biochem 68: 981-1003.

Katayama Y, Ito T, Hiramatsu K (2000) A new class of genetic element staphylococcus cassette chromosome mec encodes methicillin resistance in Staphylococcus aureus. Antimicrob Agents Chemother 44: 1549-1555.

Katayama Y, Ito T, Hiramatsu K (2001) Genetic organization of the chromosome region surrounding mecA in clinical staphylococcal strains: role of IS431-mediated mecI deletion in expression of resistance in mecA-carrying low-level methicillin-resistant Staphylococcus haemolyticus. Antimicrob Agents Chemother 45: 1955-1963.

Katayama Y, Robinson DA, Enright MC, Chambers HF (2005) Genetic background affects stability of mecA in Staphylococcus aureus. J Clin Microbiol 43: 2380-2383.

Kluytmans J, van BA, Verbrugh H (1997) Nasal carriage of Staphylococcus aureus: epidemiology underlying mechanisms associated risks. Clin Microbiol Rev 10: 505-520.

Kobayashi N, Urasawa S, Uehara N, Watanabe N (1999) Distribution of insertion sequence-like element IS1272 and its position relative to methicillin resistance genes in clinically important Staphylococci. Antimicrob Agents Chemother 43: 2780-2782.

Komatsuzawa H, Suzuki J, Sugai M, Miyake Y, Suginaka H (1994) The effect of Triton X-100 on the in-vitro susceptibility of methicillin-resistant Staphylococcus aureus to oxacillin. J Antimicrob Chemother 34: 885-897.

Kotzin BL, Leung DY, Kappler J, Marrack P (1993) Superantigens and their potential role in human disease. Adv Immunol 54: 99-166.

Kurlenda J, Grinholc M, Jasek K, Wegrzyn G (2007) RAPD typing of methicillin-resistant Staphylococcus aureus: a 7-year experience in a Polish hospital. Med Sci Monit 13: MT13-MT18.

Kurlenda J, Grinholc M, Krzyszton-Russjan J, Wisniewska K (2009) Epidemiological investigation of nosocomial outbreak of staphylococcal skin diseases in neonatal ward. Antonie Van Leeuwenhoek 95: 387-394.

Kuroda M, Ohta T, Uchiyama I, Baba T, Yuzawa H, Kobayashi I et al. (2001) Whole genome sequencing of meticillin-resistant Staphylococcus aureus. Lancet 357: 12251240.

Kwan T, Liu J, DuBow M, Gros P, Pelletier J (2005) The complete genomes and proteomes of 27 Staphylococcus aureus bacteriophages. Proc Natl Acad Sci USA 102: 5174-5179.

Labischinski H (1992) Consequences of the interaction of beta-lactam antibiotics with penicillin binding proteins from sensitive and resistant Staphylococcus aureus strains. Med Microbiol Immunol 181: 241-265.

Lannergard J, von EC, Sander G, Cordes T, Seggewiss J, Peters G et al. (2008) Identification of the genetic basis for clinical menadione-auxotrophic small-colony variant isolates of Staphylococcus aureus. Antimicrob Agents Chemother 52: 4017-4022.

Lim D, Strynadka NC (2002) Structural basis for the beta lactam resistance of PBP2a from methicillin-resistant Staphylococcus aureus. Nat Struct Biol 9: 870-876.

Lindsay JA, Holden MT (2004) Staphylococcus aureus: superbug super genome? Trends Microbiol 12: 378-385.

Lindsay JA, Ruzin A, Ross HF, Kurepina N, Novick RP (1998) The gene for toxic shock toxin is carried by a family of mobile pathogenicity islands in Staphylococcus aureus. Mol Microbiol 29: 527-543.

Liu GY, Essex A, Buchanan JT, Datta V, Hoffman HM, Bastian JF et al. (2005) Staphylococcus aureus golden pigment impairs neutrophil killing and promotes viru- 
lence through its antioxidant activity. J Exp Med 202: 209-215.

Mallorqui-Fernandez G, Marrero A, Garcia-Pique S, Garcia-Castellanos R, Gomis-Ruth FX (2004) Staphylococcal methicillin resistance: fine focus on folds and functions. FEMS Microbiol Lett 235: 1-8.

Mann NH (2008) The potential of phages to prevent MRSA infections. Res Microbiol 159: 400-405.

Menestrina G, Serra MD, Prevost G (2001) Mode of action of beta-barrel pore-forming toxins of the staphylococcal alpha-hemolysin family. Toxicon 39: 1661-1672.

Milheirico C, Oliveira DC, de LH (2007) Update to the multiplex PCR strategy for assignment of mec element types in Staphylococcus aureus. Antimicrob Agents Chemother 51: 3374-3377.

Morfeldt E, Taylor D, von Gabain A, Arvidson S (1995) Activation of alpha-toxin translation in Staphylococcus aureus by the trans-encoded antisense RNA, RNAIII. EMBO J 14: 4569-4577.

Murakami K, Tomasz A (1989) Involvement of multiple genetic determinants in high-level methicillin resistance in Staphylococcus aureus. J Bacteriol 171: 874-879.

Niemeyer DM, Pucci MJ, Thanassi JA, Sharma VK, Archer GL (1996) Role of mecA transcriptional regulation in the phenotypic expression of methicillin resistance in Staphylococcus aureus. J Bacteriol 178: 5464-5471.

Noto MJ, Kreiswirth BN, Monk AB, Archer GL (2008) Gene acquisition at the insertion site for SCCmec the genomic island conferring methicillin resistance in Staphylococcus aureus. J Bacteriol 190: 1276-1283.

Novick RP (1989) Staphylococcal plasmids and their replication. Annu Rev Microbiol 43: 537-565.

Novick RP (2003a) Autoinduction and signal transduction in the regulation of staphylococcal virulence. $\mathrm{Mol}$ Microbiol 48: 1429-1449.

Novick RP (2003b) Mobile genetic elements and bacterial toxinoses: the superantigen-encoding pathogenicity islands of Staphylococcus aureus. Plasmid 49: 93-105.

Novick RP, Geisinger E (2008) Quorum sensing in staphylococci. Annu Rev Genet 42: 541-564.

Okuma K, Iwakawa K, Turnidge JD, Grubb WB, Bell JM, O'Brien FG et al. (2002) Dissemination of new methicillin-resistant Staphylococcus aureus clones in the community. J Clin Microbiol 40: 4289-4294.

Oliveira DC, Tomasz A, de Lencastre H (2001) The evolution of pandemic clones of methicillin-resistant Staphylococcus aureus: identification of two ancestral genetic backgrounds and the associated mec elements. Microb Drug Resist 7: 349-361.

Patti JM, Bremell T, Krajewska-Pietrasik D, Abdelnour A, Tarkowski A, Ryden C, Hook M (1994) The Staphylococcus aureus collagen adhesin is a virulence determinant in experimental septic arthritis. Infect Immun 62: 152-161.

Pinho MG, Filipe SR, de Lencastre H, Tomasz A (2001) Complementation of the essential peptidoglycan transpeptidase function of penicillin-binding protein 2 (PBP2) by the drug resistance protein PBP2A in Staphylococcus aureus. J Bacteriol 183: 6525-6531.

Potempa J, Fedak D, Dubin A, Mast A, Travis J (1991) Proteolytic inactivation of alpha-1-anti-chymotrypsin. Sites of cleavage and generation of chemotactic activity. J Biol Chem 266: 21482-21487.

Proctor RA, van Langevelde P, Kristjansson M, Maslow JN, Arbeit RD (1995) Persistent and relapsing infections associated with small-colony variants of Staphylococcus aureus. Clin Infect Dis 20: 95-102.

Proctor RA, von Eiff C, Kahl BC, Becker K, McNamara P, Herrmann M, Peters G (2006) Small colony variants: a pathogenic form of bacteria that facilitates persistent and recurrent infections. Nat Rev Microbiol 4: 295-305.

Rice LB (2006) Antimicrobial resistance in gram-positive bacteria. Am J Med 119: S11-S19.

Robinson DA, Enright MC (2003) Evolutionary models of the emergence of methicillin-resistant Staphylococcus aureus. Antimicrob Agents Chemother 47: 3926-3934.

Rohde H, Knobloch JK, Horstkotte MA, Mack D (2001) Correlation of Staphylococcus aureus icaADBC genotype and biofilm expression phenotype. J Clin Microbiol 39: 4595-4596.

Rohrer S, Maki H, Berger-Bachi B (2003) What makes resistance to methicillin heterogeneous? J Med Microbiol 52: 605-607.

Rosato AE, Craig WA, Archer GL (2003a) Quantitation of mecA transcription in oxacillin-resistant Staphylococcus aureus clinical isolates. J Bacteriol 185: 3446-3452.

Rosato AE, Kreiswirth BN, Craig WA, Eisner W, Climo MW, Archer GL (2003b) mecA-blaZ corepressors in clinical Staphylococcus aureus isolates. Antimicrob Agents Chemother 47: 1460-1463.

Ruzin A, Lindsay J, Novick RP (2001) Molecular genetics of SaPI1 - a mobile pathogenicity island in Staphylococcus aureus. Mol Microbiol 41: 365-377.

Ryan KJ, Ray CG (2004) Sherris Medical Microbiology: An Introduction to Infectious Diseases. 4th edn. McGraw Hill Publishers.

Safo MK, Ko TP, Musayev FN, Zhao Q, Wang AH, Archer GL (2006) Structure of the MecI repressor from Staphylococcus aureus in complex with the cognate DNA operator of mec. Acta Crystallogr Sect F Struct Biol Cryst Commun 62: 320-324.

Scheffers DJ, Pinho MG (2005) Bacterial cell wall synthesis: new insights from localization studies. Microbiol Mol Biol Rev 69: 585-607.

Schito GC (2006) The importance of the development of antibiotic resistance in Staphylococcus aureus. Clin Microbiol Infect 12 (Suppl 1): 3-8.

Switalski LM, Patti JM, Butcher W, Gristina AG, Speziale P, Hook M (1993) A collagen receptor on Staphylococcus aureus strains isolated from patients with septic arthritis mediates adhesion to cartilage. Mol Microbiol 7: 99-107.

Tomasz A, Nachman S, Leaf H (1991) Stable classes of phenotypic expression in methicillin-resistant clinical isolates of staphylococci. Antimicrob Agents Chemother 35: 124-129.

Ubeda C, Maiques E, Knecht E, Lasa I, Novick RP, Penades JR (2005) Antibiotic-induced SOS response promotes horizontal dissemination of pathogenicity island-encoded virulence factors in staphylococci. Mol Microbiol 56: 836-844.

Vollmer W, Blanot D, de Pedro MA (2008) Peptidoglycan structure and architecture. FEMS Microbiol Rev 32: 149167.

von Eiff C (2008) Staphylococcus aureus small colony variants: a challenge to microbiologists and clinicians. Int $J$ Antimicrob Agents 31: 507-510.

Wang QM, Peery RB, Johnson RB, Alborn WE, Yeh WK, Skatrud PL (2001) Identification and characterization of a monofunctional glycosyltransferase from Staphylococcus aureus. J Bacteriol 183: 4779-4785.

Wegrzyn G (2005) What does "plasmid biology" currently mean? Summary of the Plasmid Biology 2004 Meeting. Plasmid 53: 14-22.

Weller TM (1999) The distribution of mecA mecR1 and mecI and sequence analysis of mecI and the mec promoter region in staphylococci expressing resistance to methicillin. J Antimicrob Chemother 43: 15-22. 
Wertheim HF, Melles DC, Vos MC, van Leeuwen W, van Belkum A, Verbrugh HA, Nouwen JL (2005) The role of nasal carriage in Staphylococcus aureus infections. Lancet Infect Dis 5: 751-762.

Wielders CL, Vriens MR, Brisse S, de Graaf-Miltenburg LA, Troelstra A, Fleer A et al. (2001) In-vivo transfer of mecA DNA to Staphylococcus aureus [corrected]. Lancet 357: 1674-1675.

Wilke MS, Lovering AL, Strynadka NC (2005) Beta-lactam antibiotic resistance: a current structural perspective. Curr Opin Microbiol 8: 525-533.

Williams RE, Jevons MP, Shooter RA, Hunter CJ, Girling JA, Griffiths JD, Taylor GW (1959) Nasal staphylococci and sepsis in hospital patients. Br Med J 2: 658-662.

Wisplinghoff $\mathrm{H}$, Rosato AE, Enright MC, Noto M, Craig W, Archer GL (2003) Related clones containing SCCmec type IV predominate among clinically significant Staphylococcus epidermidis isolates. Antimicrob Agents Chemother 47: 3574-3579.
Wu SW, de Lencastre H, Tomasz A (2001) Recruitment of the mecA gene homologue of Staphylococcus sciuri into a resistance determinant and expression of the resistant phenotype in Staphylococcus aureus. J Bacteriol 183: 2417-2424.

Zhang HZ, Hackbarth CJ, Chansky KM, Chambers HF (2001) A proteolytic transmembrane signaling pathway and resistance to beta-lactams in staphylococci. Science 291: 1962-1965.

Zhang K, McClure JA, Elsayed S, Conly JM (2009) Novel staphylococcal cassette chromosome mec type tentatively designated type VIII harboring class A mec and type $4 \mathrm{ccr}$ gene complexes in a Canadian epidemic strain of methicillin-resistant Staphylococcus aureus. Antimicrob Agents Chemother 53: 531-540.

Zygmunt DJ, Stratton CW, Kernodle DS (1992) Characterization of four beta-lactamases produced by Staphylococcus aureus. Antimicrob Agents Chemother 36: 440-445. 